OPEN ACCESS

Edited by: Javier A. Bravo, Pontificia Universidad Católica de Valparaíso, Chile

Reviewed by: Nazareno Paolocci, Johns Hopkins University, United States Zhiping Liu, Augusta University, United States

${ }^{*}$ Correspondence: Alexis A. Gonzalez alexis.gonzalez@pucv.cl

Specialty section: This article was submitted to Translational Pharmacology, a section of the journal Frontiers in Pharmacology

Received: 10 October 2018 Accepted: 21 June 2019 Published: 23 July 2019

Citation:

Reyes-Martinez C, Nguyen QM Kassan M and Gonzalez AA (2019) (Pro)renin Receptor-Dependent Induction of Profibrotic Factors is Mediated by COX-2/EP4/NOX-4/Smad Pathway in Collecting Duct Cells.

Front. Pharmacol. 10:803 doi: 10.3389/fphar.2019.00803

\section{(Pro)renin Receptor-Dependent Induction of Profibrotic Factors Is Mediated by COX-2/EP4/NOX-4/ Smad Pathway in Collecting Duct Cells}

\author{
Cristian Reyes-Martinez ${ }^{1}$, Quynh My Nguyen ${ }^{2}$, Modar Kassan ${ }^{3}$ and Alexis A. Gonzalez ${ }^{1 *}$ \\ ${ }^{1}$ Instituto de Química, Pontificia Universidad Católica de Valparaíso, Valparaiso, Chile, ${ }^{2}$ Skaggs School of Pharmacy and \\ Pharmaceutical Sciences, University of California, San Diego, San Diego, CA, United States, ${ }^{3}$ Cardiovascular Division, Department \\ of Medicine, Abboud Cardiovascular Research Center, University of Iowa Carver College of Medicine, lowa City, IA, United States
}

The binding of prorenin to the (pro)renin receptor (PRR) triggers the activation of MAPK ERK1/2 pathway, induction of cyclooxygenase-2 (COX-2), NOX-4-dependent production of reactive oxygen species (ROS), and the induction of transforming growth factor $\beta$ (TGF- $\beta$ ) and profibrotic factors connecting tissue growth factor (CTGF) and plasminogen activator inhibitor (PAI-I) in collecting duct (CD) cells. However, the role of COX-2 and the intracellular pathways involved are not clear. We hypothesized that the PRR activation increases profibrotic factors through COX-2-mediated PGE2 activation of E prostanoid receptor 4 (EP4), upregulation of NOX-4/ROS production, and activation of Smad pathway in mouse CD cells. Recombinant prorenin increased ROS production and protein levels of CTGF, PAI-I, and TGF- $\beta$ in M-1 CD cell line. Inhibition of MAPK, NOX-4, and COX-2 prevented this effect. Inhibition of MEK, COX-2, and EP4 also prevented the upregulation of NOX-4. Because TGF- $\beta$ activates Smad pathway, we evaluate the phosphorylation of Smad2 and 3. COX-2 inhibition or EP4 antagonism significantly prevented phosphorylation of Smad 2/3. Mice that were infused with recombinant prorenin showed an induction in the expression of CTGF, PAI-I, TGF- $\beta$, fibronectin, and collagen I in isolated collecting ducts as well as the expression of alpha smooth muscle actin ( $\alpha$-SMA) in renal tissues. COX-2 inhibition prevented this induction. These results indicate that the induction of TGF- $\beta$, CTGF, PAI-I, and ROS occurs through PRR-dependent activation of MAPK and NOX-4; however, this mechanism depends on COX-2-derived PGE2 production and the activation of EP4 and Smad pathway.

Keywords: (Pro)renin receptor, cyclooxygenase inhibition, reactive oxygen species, intrarenal renin-angiotensin system, collecting duct renin

\section{INTRODUCTION}

The binding of prorenin to the (pro)renin receptor (PRR) triggers the phosphorylation of mitogenactivated protein kinases/extracellular regulated kinases 1/2 (MAPK/ERK1/2) (Batenburg et al., 2007; Feldt et al., 2008; Muller et al., 2008; Ballarin-Gonzalez et al., 2013) and upregulates cyclooxygenase-2 (COX-2) in kidney tissues (Kaneshiro et al., 2006). We have reported that PRR 
activation by recombinant prorenin increases COX-2 expression independently of angiotensin (ANG) II in cultured renal collecting duct (CD) cells (Gonzalez et al., 2013). Both activation and upregulation of PRR have been associated with renal tissue damage (Kaneshiro et al., 2006; Kaneshiro et al., 2007; Ichihara et al., 2008). Liu showed that proximal tubular cells treated with prorenin show upregulation of transforming growth factor beta (TGF-b1) and alpha-smooth muscle actin ( $\alpha$-SMA) (Yisireyili et al., 2014). In human kidney embryonic (HEK) cells, augmentation of reactive oxygen species (ROS) is observed after PRR stimulation. This effect is mediated by a NOX-4-dependent mechanism (Clavreul et al., 2011).

We recently showed that cultured CD cells treated with nanomolar concentrations of recombinant prorenin undergo to epithelial-mesenchymal transition and have increased levels of intracellular ROS, activation of MAPK pathway, and upregulation of profibrotic factors including CTGF, plasminogen activator inhibitor-1 (PAI-I) and TGF- $\beta$, fibronectin, and collagen I (Gonzalez et al., 2017). Although there are still a discrepancy between the plasma levels of prorenin and the effective physiological concentrations for PRR activation in the kidney (Campbell et al., 2009), it has been shown that high plasma prorenin is present in patients with diabetic nephropathy (Franken et al., 1992), a condition that is associated with microvascular pathologies (Chiarelli et al., 2001). PRR contributes to development of diabetic kidney disease through TGF- $\beta$ and connective tissue growth factor (CGTF) signaling cascade (Huang et al., 2011). Yoshida et al. demonstrated that high plasma prorenin plays a role in the development of coronary artery disease (Yoshida et al., 2015). Interestingly, it has been shown that African-Americans who have known susceptibility to high blood pressure showed disproportionately high levels of prorenin (Tu et al., 2012).

In diabetic animal models, there is an increase in prorenin and renin expression in the CD (Kang et al., 2008). Because PRR is expressed in the neighbor CD intercalated cell (Gonzalez et al., 2013), prorenin or renin coming from the principal cells of the CD might stimulate PRR, leading to activation of signaling pathways such as MAPK/ERK 1/2 and induction of COX-2. Although the events that follow the activation of PRR on ROS generation, MAPK pathway activation, and upregulation of profibrotic genes have been partially described (Clavreul et al., 2011; Gonzalez et al., 2017), the role of COX-2 in this regulation is not fully understood. It has been shown that the ERK1/2 pathway and cAMP/PKA pathway increase the expression of NOX-4 (Clavreul et al., 2011; Muzaffar et al., 2012). Activation of the Gs (cAMP/PKA) coupled prostaglandin receptor EP4 increases NOX-4 expression in liver cells. In addition, overexpression of COX-2 shows higher NOX4 levels and ROS content, while the presence of a COX-2 inhibitor decreases these effects (Sancho et al., 2011). Reactive oxygen species (ROS) are involved in TGF- $\beta$ and Smad signaling (Lafon et al., 1996; Hong et al., 1997; Chiu et al., 2001), which are known to be activators of fibrotic factors such as CTGF and PAI-I (Clarkson et al., 1999; Kilari et al., 2018). The ERK pathway can enhance Smad activity. Additionally, ERK inhibition reduces TGF- $\beta 1$-stimulated Smad phosphorylation as well as collagen production and promoter activities, suggesting that
ERK activity is necessary for an optimal response to TGF- $\beta 1$ (Hayashida et al., 2003).

In the present study, we aimed to demonstrate that the activation of PRR increases profibrotic factors through COX2-mediated $\mathrm{PGE}_{2}$ activation of $\mathrm{E}$ prostanoid receptor 4 (EP4), the upregulation of NOX-4/ROS production, and activation of Smad pathway in mouse CD cells. To test this, M-1 CD cell line was treated with recombinant prorenin with and without inhibition of MAPK pathway, NOX-4 and COX-2. Specific pharmacological blockade of EP4 receptor was also tested in M-1 cells incubated with hrPR. Since Smad 2 and 3 are considered as downstream mediators of TGF- $\beta$ signaling (Meng et al., 2015) and because TGF- $\beta$ is induced by ROS, we evaluated the phosphorylation of Smad 2 and 3 , which are activated by TGF- $\beta$ receptor in the presence of EP 4 antagonist. Additionally, we performed in vivo experiments in mice infused with human recombinant prorenin (100 $\mathrm{ng} / \mathrm{min}) \mathrm{via}$ an osmotic minipump for $36 \mathrm{~h}$ with and without selective COX-2 inhibitor. The expression of profibrotic factors was analyzed in isolated CDs and renal medullary tissues.

\section{MATERIALS AND METHODS}

\section{M-1 Cell Culture}

M-1 cells (ATCC, VA) are a CD cell line with phenotypic characteristics of cortical CD cells (Stoos et al., 1991). M-1 cells are composed of principal cells and intercalated cells constitutively expressing COX-2 (Nasrallah et al., 2001), prorenin-renin, and PRR constitutively (Gonzalez et al., 2015; Gonzalez et al., 2017; Gonzalez et al., 2017). The M-1 cells were cultured as previously described (Gonzalez et al., 2015; Gonzalez et al., 2016; Gonzalez et al., 2017). Cells were harvested after $6 \mathrm{~h}$ of treatments with human recombinant prorenin (hrPR) (Cayman Chemical, EE.UU). at $10^{-8} \mathrm{~mol} / \mathrm{l}$ according to its described range of affinity in nanomolar range (Batenburg et al., 2007; Wilkinson-Berka, 2008)

\section{Pharmacological Blockers in M-1 Cells}

Treatment with NOX-4 inhibitor GKT 137831 was performed at three different concentrations $(10,20$, and $30 \mu \mathrm{M})$ to explore the effect on ROS production according to the literature (Sedeek et al., 2013a). GKT 137831 was then used at $30 \mu \mathrm{M}$ for protein expression analysis. Similarly, we tested the effects of PD98059, a potent and selective inhibitor of MAP kinase kinases (MAPKK), MEK1 and MEK2 (Alessi et al., 1995) at two concentrations (30 and $50 \mu \mathrm{M}$ ) (Gonzalez et al., 2017), to explore the effects on ROS production and induction of profibrotic proteins mediated by hrPR. NS-398 was used at $10^{-5} \mathrm{~mol} / \mathrm{l}$ (Ferguson et al., 1999) to determine COX-2 inhibition effect on ROS and profibrotic protein expression. CD cells show high expression of EP4 receptors (Gonzalez et al., 2013; Wang et al., 2016). We used L-161982 (Cayman Chemical), a potent and selective EP4 receptor antagonist that demonstrates selective binding to human EP4 receptors with a Ki value of $0.024 \mathrm{M}$. We used a fourfold higher concentration $(100 \mathrm{nM})$ (Takayama et al., 2002). All pharmacological inhibitors 
were added 30 min before incubations with hrPR. M-1 CD cells were harvested after $6 \mathrm{~h}$. Controls were performed with vehicle (DMSO, 0.06\% vol/vol).

\section{Measurement of Reactive Oxygen Species in $\mathbf{M}-1$ Cells}

M-1 cells were seeded in 96-well black polystyrene plates and treated with MEK, COX-2, or NOX-4 inhibitors during $15 \mathrm{~min}$ at $37^{\circ} \mathrm{C}$. Then, all groups were treated with probe carboxy- $2^{\prime}$, $7^{\prime}$-dichloro-dihydro-fluorescein diacetate (DCFHDA, Sigma Chemical Co, St. Louis, MO, USA) at $25 \mu \mathrm{M}$ for $30 \mathrm{~min}$ at $37^{\circ} \mathrm{C}$. Fluorescence measurements of DCF (the product of H2DCFDA oxidation: excitation, $495 \mathrm{~nm}$; emission, $529 \mathrm{~nm}$ ) were performed on a plate reader (Appliskan; Thermo Fisher Scientific, Waltham, MA, USA). To normalize results, total protein from each well was quantified by the bicinchoninic acid (BCA) method. A positive control was conducted using $50 \mu \mathrm{M} \mathrm{H}_{2} \mathrm{O}_{2}$.

\section{In Vivo Treatments}

The Institutional Animal Care and Use Committees approved all animal protocols. Male CF-1 mice (18-20 g, $n=5)$ were cage housed and maintained in a temperature-controlled room with 12-h light/dark cycles with free access to tap water and standard rat chow. Experiments with chronic infusions of prorenin have been performed previously in rhesus monkeys at $400 \mathrm{ng} / \mathrm{min}$, causing three- to fourfold increases in normal plasma prorenin concentrations from $\sim 70$ to $\sim 250 \mathrm{ng} / \mathrm{ml} / \mathrm{h}$ (Lenz et al., 1990). High plasma prorenin, as high as $\sim 1,000 \mathrm{pg} / \mathrm{ml}$, has been found in patients with cardiovascular risk (Yoshida et al., 2015). Human recombinant prorenin (Cayman Chemicals) was infused at a rate of $100 \mathrm{ng} / \mathrm{min}$ via osmotic minipump for $36 \mathrm{~h}$. Selective COX-2 inhibitor NS-398 attenuates myocardial fibrosis in mice at $5 \mathrm{mg} \mathrm{kg}$ (Chi et al., 2017) and is able to block the LPS-induced increase in $\mathrm{PGE}_{2}$ in rats at same dose (Lugarini et al., 2002). NS-398 (Cayman Chemicals, EE.UU). was administered in 5\% aqueous methylcellulose solution by oral gavage every $6 \mathrm{~h}$. Sham-operated mice were used as controls and administered methylcellulose solution. For physiological parameters presented in Table 1, four mice were placed in cages for urine collections. Urine osmolality was measured by vapor pressure osmometry (Vapro Osmometer, model 5600, Wescor). Creatinine measurements in plasma and urine were used to calculate the estimated creatinine clearance over $16 \mathrm{~h}$ as an approach to determine renal function. Urinary sodium and potassium were measured as described previously (Gonzalez et al., 2014).

\section{Immunofluorescence in Freshly Isolated Collecting Ducts}

At the end of the study, mice were euthanized by conscious decapitation, and renal tissues were collected to perform immunofluorescence and Western blots in freshly isolated inner medullary collecting ducts. Freshly isolated collecting ducts were prepared as previously described (Gonzalez et al., 2011), with variations in digestion time and wash steps. Briefly, inner medullary tissues were digested in $10 \mathrm{ml}$ of DMEM-Ham F-12, $20 \mathrm{mg}$ of collagenase $\mathrm{B}, 7 \mathrm{mg}$ of hyaluronidase, $80 \mathrm{mmol} / \mathrm{l}$ of urea, and $130 \mathrm{mmol} / \mathrm{l}$ of $\mathrm{NaCl}$ and incubated at $37^{\circ} \mathrm{C}$ under continuous agitation for $30 \mathrm{mi}$. After centrifugation, the pellet was washed in prewarmed culture medium without enzymes. The resulting IMCD cell suspension was seeded in six-well chambers (Nalge Nunc, Rochester, NY, USA) and fixed in cold methanol for $20 \mathrm{~min}$, blocked with PBS-Tween (0.1\%) plus BSA (3\%) for $1 \mathrm{~h}$, and stained with anti-fibronectin (Cat. No. sc-8422; Santa Cruz Biotechnology) or anti-collagen I antibody (Cat. No. 34710, Abcam) at 1:200 dilutions and detected with secondary antibody Alexa Fluor 488 conjugated to anti-rabbit IgG (Invitrogen) at 1:500 dilutions. Negative controls were obtained by omission of the specific primary antibody. Measurements of fluorescence intensity were performed with NIS Elements software (Nikon) in 10 fields from each processed kidney and expressed as fluorescence intensity versus total number of collecting duct in each field previously counted in light field (Figure 5B).

\section{Tissue Immunofluorescence}

Kidney sections $(3 \mu \mathrm{m})$ were stained with rabbit anti-PRR (Cat. No. HPA003156, Sigma Chemical Co, St. Louis, MO, USA) at 1:200 dilutions or $\alpha$-SMA antibody from Abcam (ab5694, Abcam, Cambridge, MA, USA) followed by the incubation of the corresponding immunofluorescent secondary antibody (1:1,000, Alexa Fluor ${ }^{\circledR}$ 594, Invitrogen, Carlsbad, CA, USA). Negative controls were obtained by omission of the specific primary antibody. Samples were counterstained with 4',6-diamidino-2-phenylindole (DAPI, Invitrogen, Carlsbad, CA, USA) for nuclei staining.

TABLE 1 | Physiological parameters in mice after $36 \mathrm{~h}$ of subcutaneous infusions with saline, human recombinant prorenin (hrRP), and hrPR plus COX-2 inhibitor NS-398.

\begin{tabular}{|c|c|c|c|c|}
\hline & Saline & hrPR & NS398 & hrPR+NS398 \\
\hline Kidney weight, g & $0.29 \pm 0.01$ & $0.30 \pm 0.02$ & $0.28 \pm 0.03$ & $0.29 \pm 0.01$ \\
\hline Urine flow, ml/16 h & $6.02 \pm 0.02$ & $5.35 \pm 0.05$ & $4.91 \pm 0.06$ & $4.21 \pm 0.10^{*}$ \\
\hline Estimated GFR, $\mathrm{ml} \cdot \mathrm{min}^{-1}$ & $0.92 \pm 0.03$ & $0.89 \pm 0.04$ & $0.86 \pm 0.05$ & $0.84 \pm 0.05^{\star}$ \\
\hline FENa \% & $0.91 \pm 0.02$ & $0.88 \pm 0.02$ & $0.87 \pm 0.02$ & $0.87 \pm 0.03$ \\
\hline FEK \% & $1.4 \pm 0.2$ & $1.3 \pm 0.3$ & $1.4 \pm 0.4$ & $1.3 \pm 0.2$ \\
\hline
\end{tabular}

${ }^{*} p<0.05$ versus Saline group. 


\section{Protein Expression Analysis}

Forty micrograms of total protein were used for Western blot analysis. Protein expression levels were quantified after immunoblotting using a 1:1,000 dilution of the following specific antibodies: connecting tissue growth factor (CTGF; Cat. No. sc-25440, Santa Cruz Biotechnology), PAI-1 (Cat. No. SC-8979, Santa Cruz Biotechnology), TGF- $\beta$ (Cat. No. SC-130348, Santa Cruz Biotechnology), COX-2 antibody (Cayman, Ann Arbor, MI, USA), mouse anti-phospho-p44/42 ERK1/2 (Thr202/Tyr204), and a rabbit anti-total ERK antibody (Cell Signaling Technology, Beverly, MA, USA). NOX-4 antibody was purchased from Santa Cruz (sc-21860). Antibodies against Anti-Smad2/3 antibody and anti p-Smad2/3 were obtained from Abcam (Abcam, Cambridge, MA, USA). Primary antibodies were followed by incubation with either donkey anti-rabbit or anti-mouse IgG IRDye $800 \mathrm{CW}$ (Santa Cruz Biotechnology) at 1:3,000 dilutions. Resulting bands were compared to molecular weight standards (M. Biosources, San Diego, CA, USA). Densitometry was performed with ImageJ software and normalized to monoclonal anti- $\beta$-actin antibody (Cat. A2228, Sigma Chemical Co, St. Louis, MO, USA).

\section{Statistical Analyses}

For Western blot, an average number of three to six independent observations was performed for each treatment and represented as fold change versus controls. For in vivo studies, five mice were used in each group. Data were evaluated by the Grubb test, followed when appropriate by paired and unpaired Student's t-test or by one-way ANOVA with Tukey post-test. Significance was defined as $p<0.05$. No significant differences are expressed as "ns". Results are expressed as mean \pm SEM.

\section{RESULTS}

\section{Recombinant Prorenin Causes ERK1/2 Phosphorylation and Increases COX-2 and NOX-2 Expression in M-1 Cells}

As previously described, treatment with recombinant prorenin induced ERK1/2 phosphorylation over the time of incubations, reaching a peak after $10 \mathrm{~min}$ of incubation. It subsequently decreased after $1 \mathrm{~h}$ (Figure 1A). After $6 \mathrm{~h}, \mathrm{COX}-2$ and NOX-4 were augmented (ratio protein $/ \beta$-actin densitometric values: $1.67 \pm 0.16$ vs. $0.66 \pm 0.08$ for COX -2 and $1.48 \pm 0.08$ vs. $0.70 \pm$ 0.19 , for NOX $4 p<0.05$ ); however, inhibition of MAPK pathway with PD98059 prevented this effect.

\section{MAPK Inhibition Impairs ROS Formation and the Upregulation of CTGF, TGF- $\beta$, and PAI-I Caused by Recombinant Prorenin Incubations}

Inhibition of MAPK pathway prevented ROS formation (Figure 2A). We tested two concentrations of PD98059:

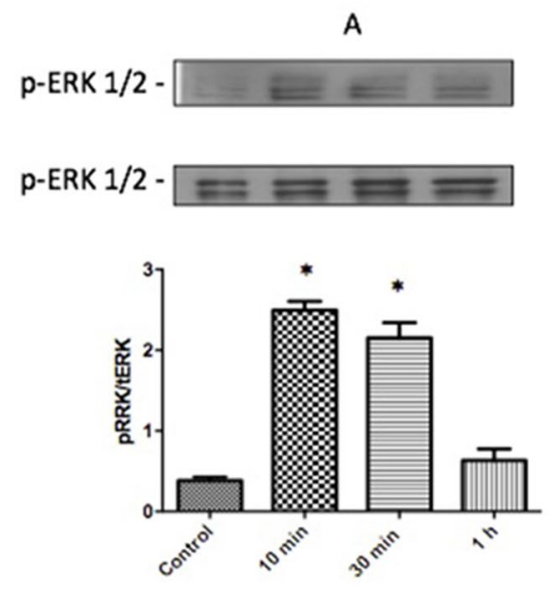

B

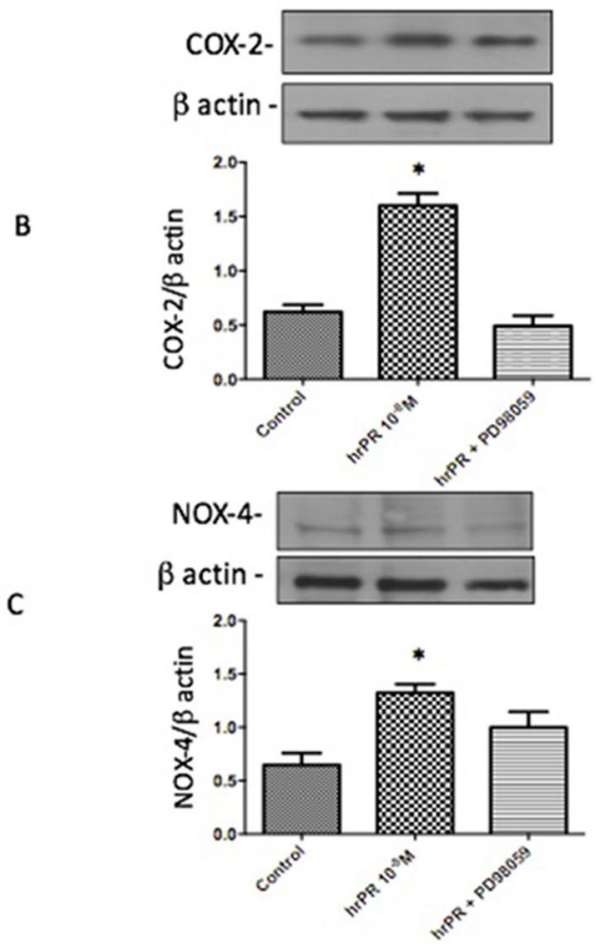

C

FIGURE 1 | Incubations with recombinant prorenin increase the abundance of COX-2 and NOX-4 via MAPK pathway in M-1 cells. (A). Time response of ERK1/2 phosphorylation after incubations with 10-8 M human recombinant prorenin (hrPR). MAPK inhibition impairs hrPR-dependent upregulation of COX-2 (B) and NOX-4 (C). ${ }^{*} p<0.05, n=4$. 
A

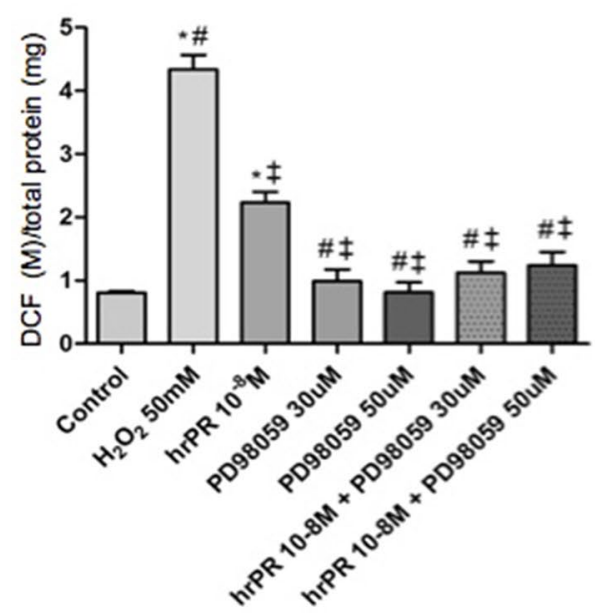

B

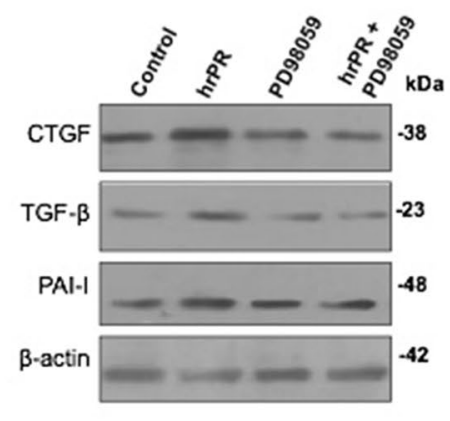

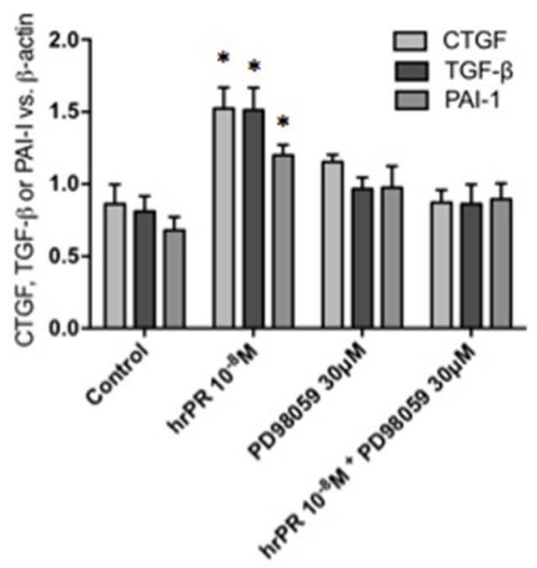

FIGURE 2 | MAPK pathway inhibition by PD98059 prevented the induction of ROS levels and profibrotic markers CTGF, TGF- $\beta$, and PAI-I. (A). For ROS quantification, M-1 cells were treated with PD98059 at 30 and $50 \mu \mathrm{M}$ during 15 min, incubated with DCFH-DA probe for 30 min, and treated with hrPR for 15 min. Results are expressed as DCF probe fluorescence intensity versus total protein (mean \pm SEM) (B). Protein levels of CTGF, TGF- $\beta$, and PAI-I represented by Western blot analysis (left) and quantitation (right) in M-1 cells incubated during 6 h with hrPR, PD98059, or hrPR plus PD98059, ${ }^{*} p<0.05$ versus control, \# $p<0,05$ versus hrPR group, $\ddagger p<0,05$ versus positive control, $n=5$.

30 and $50 \mathrm{mmol} / \mathrm{l}$. No differences were found between both concentrations in the blunted effect on hrPR-dependent induction of ROS (control: $0.80 \pm 0.01$; hrPR: $2.22 \pm 0.21, p<$ 0.05 vs. control; PD98059 $30 \mathrm{mmol} / \mathrm{l}: 1.24 \pm 0.17, p=\mathrm{ns}$ vs. control; PD98059 $50 \mathrm{mmol} / \mathrm{l}: 1.12 \pm 0.12, p=\mathrm{ns}$ vs. control). Induction of CTGF, TGF- $\beta$, and PAI-I was prevented by MAPK inhibition (ratio protein $/ \beta$-actin densitometric values: $0.87 \pm 0.18,0.86 \pm 0.22,0.90 \pm 0.19$, respectively, $p=\mathrm{ns}$ ); see Figure 2B for immunoblot analysis.

\section{Induction of ROS and Profibrotic Protein Expression Is Prevented by Inhibition of NOX-4}

Figure $3 \mathrm{~A}$ shows the effect of NOX-4 inhibition in M-1 CD cells incubated with human recombinant prorenin (hrPR) at $10^{-8} \mathrm{~mol} / \mathrm{l}$. Treatment with $\mathrm{hrPR}$ increased $\mathrm{DCF} /$ protein ratio $(2.15 \pm 0.23$ vs. $0.68 \pm 0.09, p<0.05)$; however, pretreatment with GTK 137831 prevented this effect at doses of $30 \mathrm{mmol} / \mathrm{l}(0.62 \pm 0.01$ vs. $0.68 \pm 0.09, p=\mathrm{ns})$ and to a lesser extent at doses of 10 and $20 \mathrm{mmol} / \mathrm{l}(1.04 \pm 0.15, p=\mathrm{ns}$ vs. control and $1.45 \pm 0.19, p<0.05$ vs. control). Afterward, the following experiments evaluating protein expression were done using $30 \mathrm{mmol} / \mathrm{l} \mathrm{GTK}$ 137831. Figure 3B shows the effects of NOX-4 inhibition on the expression of CTGF, PAII, and TGF- $\beta$ in M-1 cells incubated with hrPR. As observed, hrPR causes a significant increase in protein levels of all three markers analyzed (ratio protein vs. $\beta$-actin densitometric values: CTGF, $1.52 \pm 0.07$ vs. $0.50 \pm 0.01, p<0.05$; TGF- $\beta$, $1.51 \pm 0.08$ vs. $0.49 \pm 0.02, p<0.05$; PAI-I, $1.21 \pm 0.02$ vs. $0.50 \pm 0.02, p<0.05)$.

\section{COX-2 Inhibition Impairs the Induction of ROS NOX-4 and Profibrotic Genes in M-1 CD Cells Treated With Recombinant Prorenin}

We performed new experiments incubating M-1 cells with hrPR or hrPR plus pre-incubations with specific COX-2 inhibitor NS-398. As shown in Figure 4A, NS-398 completely blunted the induction of NOOX-4 protein expression at $10^{-5}$ $M$. The increases in intracellular ROS caused by hrPR were also blunted by NS-398 (control: $0.51 \pm 0.01$; hrPR: $2.15 \pm 0.18, p<$ 0.05 vs. control; hrPR+NS-398: $0.64 \pm 0.08, p=$ ns vs. control, Figure 4B). Similarly, the induction of CTGF, TGF- $\beta$, and PAI-I was prevented by MAPK inhibition (ratio protein $/ \beta$-actin densitometric values: $0.87 \pm 0.18,0.86 \pm 0.22,0.90 \pm 0.19, p=\mathrm{ns}$ vs. control group, Figure 4C).

\section{EP4 Receptor Antagonism Decreases ROS Production, NOX-4 Expression, Induction of TGF- $\beta$, CTGF, and PAI-I, and Activation of the Smad Pathway in M-1 Cells Incubated With hrPR}

We next tested if pharmacological blockade of the EP4 receptor would be able to prevent ROS formation and the induction of TGF- $\beta$, CTGF, and PAI-I in M-1 cells incubated with hrPR. As shown in Figure 5A, ROS production was ameliorated in M-1 cells that were treated with hrPR and pre-incubated with L-161982 at $10^{-7} \mathrm{M}$. The EP4 receptor antagonist partially prevented the induction of TGF- $\beta$, CTGF, and PAI-I (Figure 5B). This was also associated with a reduction in the protein expression of NOX-4 (Figure 5C). EP4 receptor antagonism prevented the 

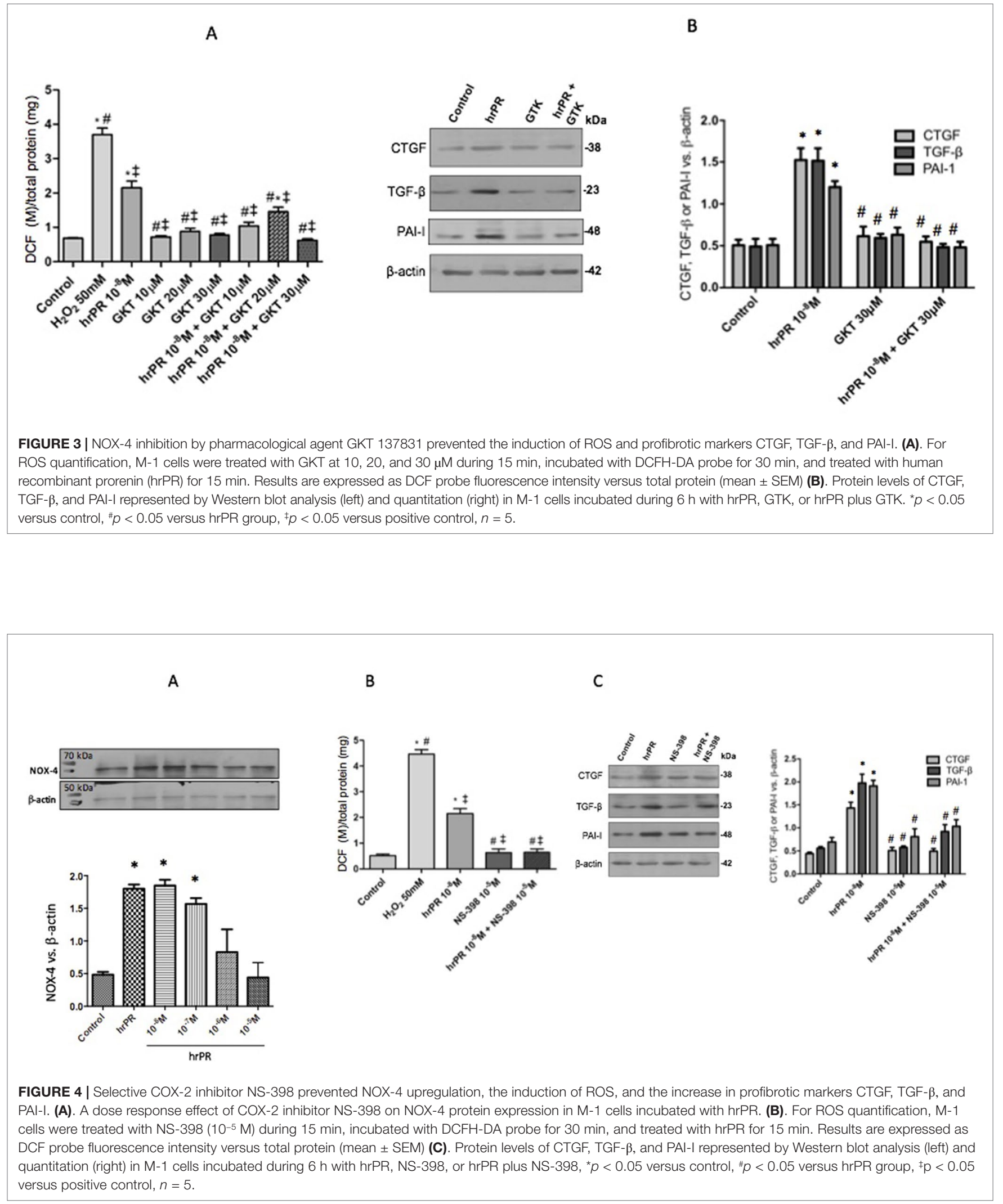


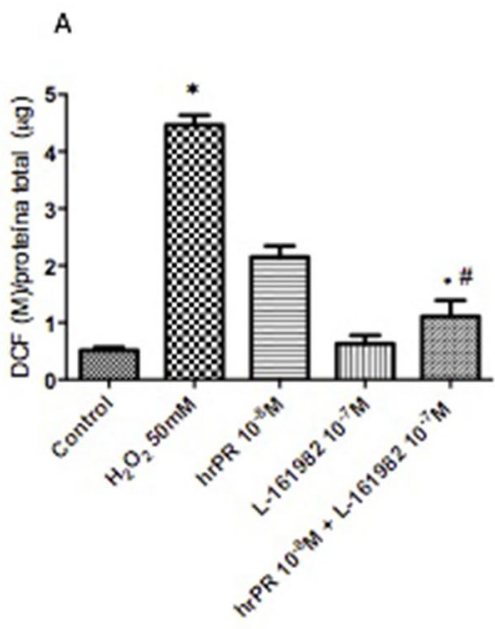

C
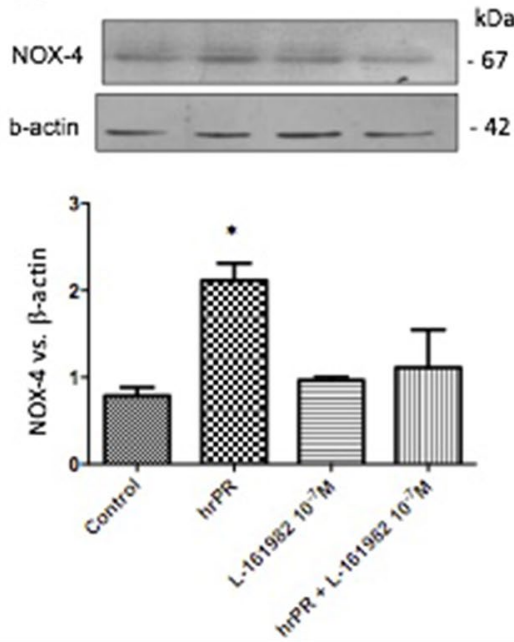
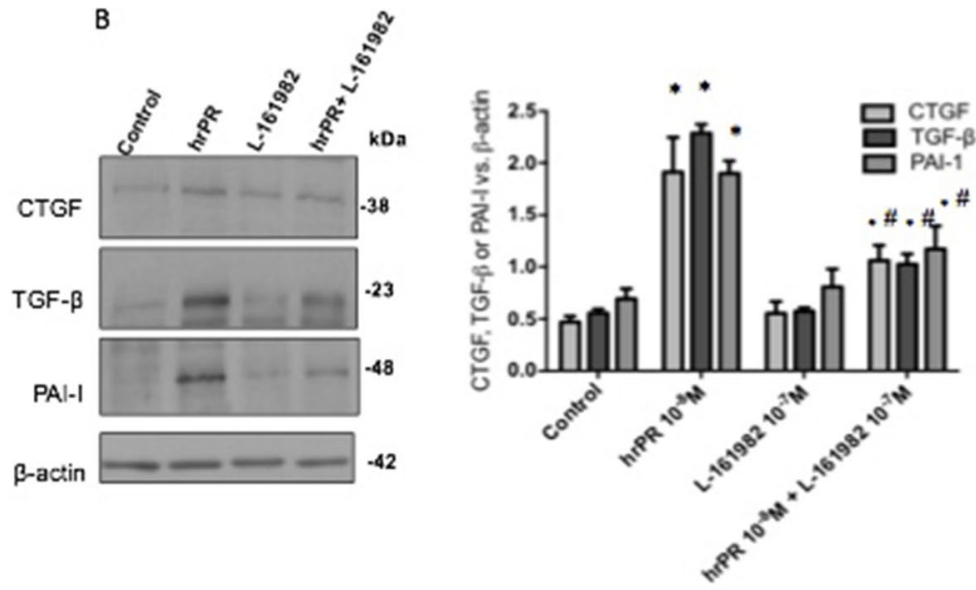

D
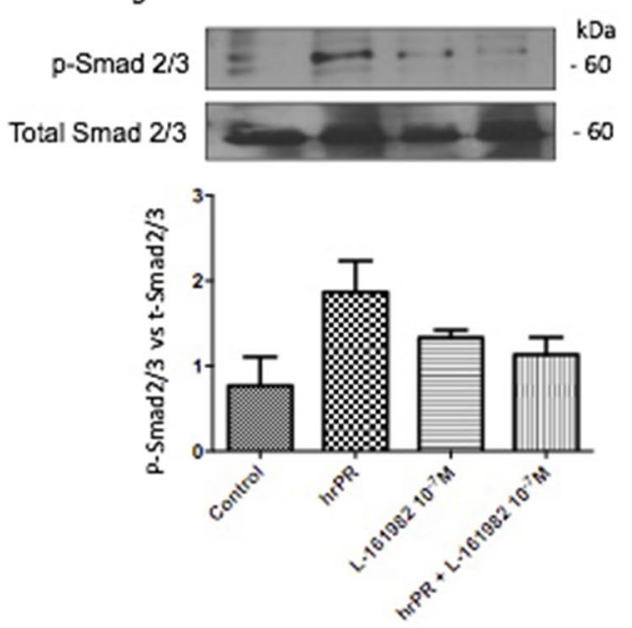

FIGURE 5 | E-Prostanoid receptor 4 blockade prevents hrPR-induced ROS accumulation, NOX-4 upregulation, and induction of profibrotic factors CTGF, TGF- $\beta$, and PAI-I. Another set of M-1 cells was tested for ROS production and protein expression of NOX-4, CTGF, TGF- $\beta$, and PAI-I. Pre-incubations with $10^{7} \mathrm{M}$ of L-161982 partially prevented ROS induction (A) and upregulation of profibrotic factors (B). NOX-4 induction was prevented by EP4 L-161982 (C). Because NOX-4 is responsible for ROS production and TGF- $\beta$ synthesis, we tested the activation of Smad pathway by examining phosphorylation of Smad 2 and 3 . Preincubations with EP4 inhibitor prevented Smad2 and 3 phosphorylation levels in response to hrPR incubations (D).

phosphorylation of Smad 2/3 (Figure 5D), indicating that the activation of TGF- $\beta$ receptor is involved in the induction of profibrotic factors.

\section{Chronic Infusion of Recombinant Prorenin Increases the Expression of CTGF, PAI-I, and TGF- $\beta$ Proteins in Medullary CDs; COX-2 Inhibition Prevents This Effect}

We tested the effect of chronic infusion of hrPR at a rate of $100 \mathrm{ng} / \mathrm{min}$, via an osmotic minipump for $36 \mathrm{~h}$ on normal and treated plasma prorenin levels. Using renin enzymatic activity, prorenin was measured in kidney homogenates as the difference between renin activity before and after trypsin activation of prorenin. Estimated plasma prorenin levels were $1,564 \pm 109$ in controls and 3,514 $\pm 201 \mathrm{in} \mathrm{hrPR-infused} \mathrm{groups}$ $(p<0.05, n=4)$. Although PRR has been described at the apical aspect of intercalated CD cells (Gonzalez et al., 2011; Gonzalez et al., 2013), it has also been described at the basolateral membrane (Wang et al., 2016). Physiological parameters such as body weight, kidney weight, urine osmolality, urine flow, $\mathrm{Na}+$ and $\mathrm{K}+$, and estimated GFR are shown in Table $\mathbf{1}$. Prorenin infusion during $36 \mathrm{~h}$ slightly reduced $\mathrm{Na}+$ excretion and significantly increased urine osmolality. As shown in Figure 6, immunofluorescence studies in kidney slides from control mice showed mostly apical distribution of PRR (in red color and arrows) surrounding the luminal aspect of the CD. Then, we expect that the actions of hrPR might be mediated through blood and filtered hrPR-dependent activation of PRR. Figure 6E shows the protocols in mice and the extractions of inner medullary CDs to perform immunoblots and immunofluorescence. Freshly isolated inner medullary CDs 

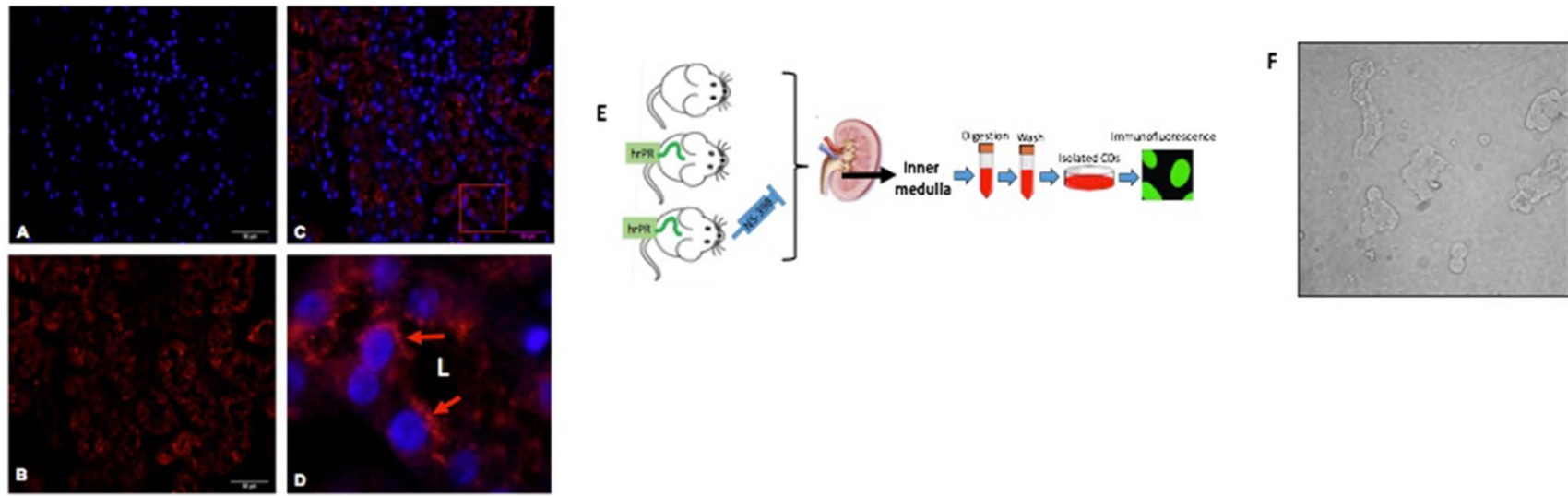
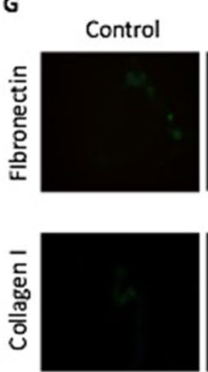

hrPR
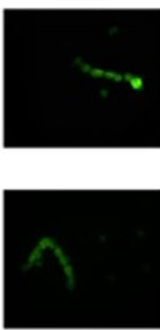

NS-398
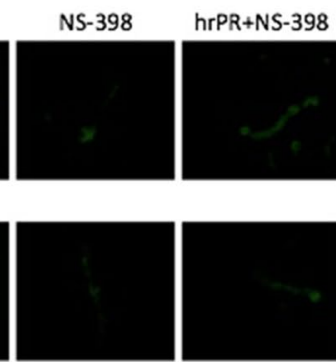

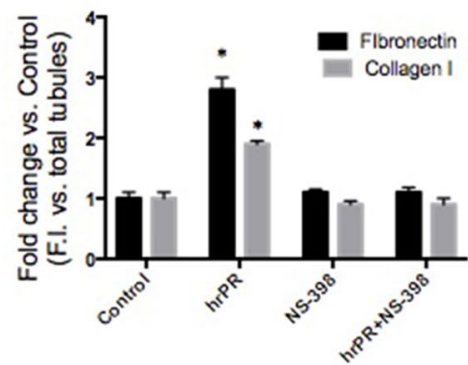

FIGURE 6 | In vivo approach to evaluate the effect of chronic hrPR infusion with or without COX-2 inhibition on the expression of collagen I, fibronectin, CTGF, TGF- $\beta$, and PAI-I in inner medullary CDs. Immunofluorescence performed in mouse kidney sections showing specific labeling of (Pro)renin receptor in the CDs. (A). DAPI staining for nuclei. (B). Anti-PRR. (C) Merge image. (D). 10x digital zoom of merged image showing apical distribution of PRR (red arrows). L indicates tubular lumen. (E). In vivo methodology. Human recombinant prorenin was infused at a rate of $100 \mathrm{ng} / \mathrm{min}$ via an osmotic minipump for $36 \mathrm{~h}$. COX-2 inhibitor NS-398 was administered at $10 \mathrm{mg} / \mathrm{kg}$ by oral gavage every $6 \mathrm{~h}$. Sham-operated mice and administered methyl cellulose solution were used as controls. At the end of the study, mice were euthanized by conscious decapitation and renal tissues collected to perform immunofluorescence and Western blots in freshly isolated inner medullary CDs. (F). Representative image of the resulting suspension of freshly isolated inner medullary CDs. (G). Inner medullary CDs were fixed, blocked, and stained with anti-fibronectin or anti-collagen I antibody and detected with secondary antibody Alexa Fluor 488 conjugated to anti-rabbit IgG. (H). Measurements of fluorescence intensity in 10 fields from each processed kidney and expressed as fluorescence intensity versus total number of CD in each field.

(Figure 6F) from chronically infused hrPR mice showed augmented fibronectin and collagen I immunofluorescence intensity as compared to controls. NS-398-treated mice did not show changes in immunofluorescence intensity when compared to controls. Mice with COX-2 inhibition treatment and hrPR infusions did not show increase in fibronectin or collagen I staining (Figures 6G, $\mathbf{H}$ ). We next examined the expression profile of phosphorylated and total ERK1/2 and profibrotic genes in renal tissues from mice. As shown in Figure 7 , the changes in CTGF, PAI-I, and TGF- $\beta$ expression in inner medullary tissues caused by hrPR infusion were accompanied by increased ERK1/2 phosphorylation (ratio protein $/ \beta$-actin densitometric values: controls, $0.67 \pm 0.01$ vs. $\mathrm{hrPR}, 1.76 \pm$ $0.02, p<0.05)$. However, despite ERK phosphorylation, the expression of CTGF, PAI-I, and TGF- $\beta$ was not different from controls in mice infused with hrPR and treated with NS-398. Positive staining for $\alpha$-SMA was present in some tubular cells but not in interstitial renal cells from mice infused with hrPR. A reduction in the staining was evidenced in mice infused with NS-398 (Figure 7C). Finally, we determined levels of IL-1 $\beta$ mRNA relative to $18 \mathrm{~S}$ mRNA as indicative of inflammatory damage. Figure 7D shows a small but significant increase in IL-1 $\beta$ (IL-1 $\beta / 18$ S mRNA, hrPR: $2.06 \pm 0.09$ vs. control: $1.21 \pm$ $0.11, p<0.05)$ that was partially prevented by COX-2 inhibition (hrPR+NS398: $1.67 \pm 0.04$ vs. hrPR: $2.06 \pm 0.09, p<0.05)$.

\section{DISCUSSION}

The possible pathological role of PRR has been under intense investigation during the last two decades. Seminal experiments showing that PRR is able to activate prorenin and renin catalytic activity (Nguyen and Burckle, 2004; Nguyen et al., 2004) pointed out its possible role in intratubular and intrarenal Ang I formation with the consequent increase in Ang II levels, contributing to the deleterious effects of Ang II such as vasoconstriction (Nguyen and Contrepas, 2008), antinatriuresis (Nguyen et al., 2002), and profibrotic signals (Clavreul et al., 2011). All these effects are especially relevant in hypertension and kidney disease. The activation of PRR by its agonists is relevant, given the evidence that shows that in diabetes, there are high levels of circulating prorenin (Franken et al., 1992; 
A

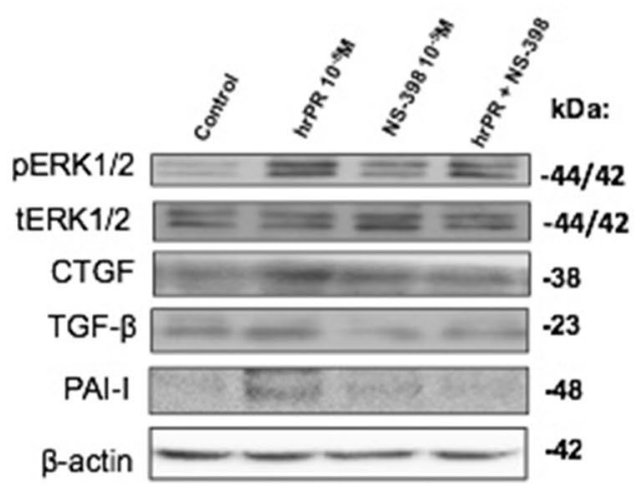

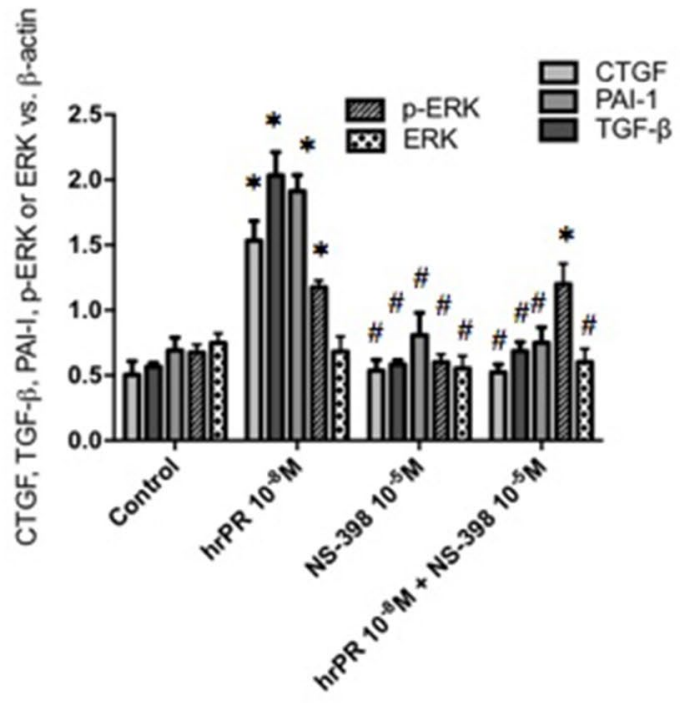

C

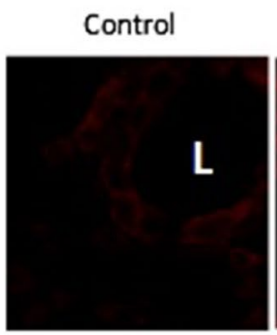

hrPR

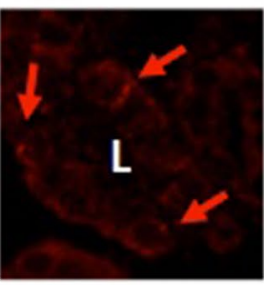

NS-398

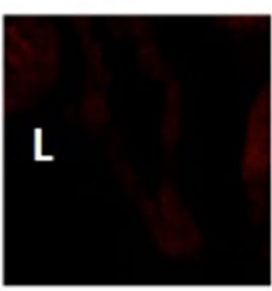

hrPR+NS-398

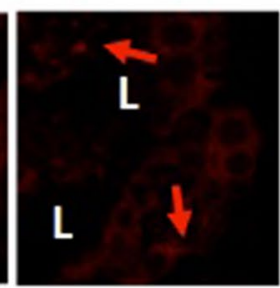

D

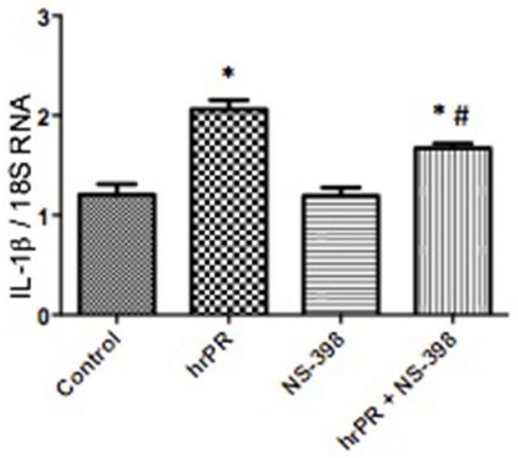

FIGURE 7 | Representative Western blot images (A) and quantitation (B) of phospho-ERK, total ERK, CTGF, TGF- $\beta$, and PAl-I in inner medullary tissues ( $n=5)$. ${ }^{*} p<0.05$ versus control, $\# p<0.05$ versus hrPR group. (C). Immunofluorescence of alpha smooth muscle actin ( $\alpha$-SMA), a fibrosis-related marker in kidney sections from control mice, saline-infused mice, and mice infused with hrPR. Staining is present in some tubular cells but not in the interstitial cells in renal slides of mice infused with hrPR. A reduced $\alpha$-SMA staining was evidenced in mice infused with NS-398. (D). IL-1 $\beta$ mRNA relative to $18 S$ mRNA as indicative of inflammatory damage. $p<0.05$ versus control, $" p<0.05$ versus hrPR group.

Chiarelli et al., 2001) and upregulation of the PRR (Huang and Siragy, 2009; Huang and Siragy, 2010). Similarly, it is suggested that high plasma prorenin concentration plays a role in the development of coronary artery disease (Yoshida et al., 2015). Transgenic rats overexpressing PRR show renal tissue damage (Kaneshiro et al., 2006) and elevated blood pressure (Burckle et al., 2006). Additionally, in animal models of diabetes and hypertension, the synthesis and secretion of prorenin and renin are greatly augmented in the principal cells of the CD (PrietoCarrasquero et al., 2004; Kang et al., 2008; Prieto-Carrasquero et al., 2008), supporting the concept of a local activation of a tubular renin-angiotensin system. Thus, the mechanisms by which PRR may influence local renin-angiotensin system and tissue damage need to be clarified.

We have previously shown that the activation of PRR increases ROS and profibrotic genes in cultured M-1 CD cell line, which supports the hypothesis that the activation of this receptor may generate renal tissue damage (Gonzalez et al., 2017). However, the exact mechanisms are still unclear. By using PRR's natural ligand prorenin (recombinant human prorenin) at nanomolar concentrations, we demonstrated that the activation of PRR activates MAPK pathway and upregulates COX-2 and NOX-4. PRR activation also promotes intracellular ROS accumulation and the upregulation of CTGF, TGF- $\beta$, and PAI- 1 . These effects are blunted by pharmacological inhibition of MAPK, NOX-4, and COX-2 enzymatic activities. Importantly, we showed that the antagonism of the E-prostanoid receptor EP4, which is a Gs-coupled receptor (Gs/cAMP/PKA pathway activator), also prevented the upregulation of NOX-4 and profibrotic factors. Interestingly, the phosphorylation of $S \operatorname{mad} 2 / 3$ was prevented by EP 4 antagonist, indicating that TGF- $\beta$ receptor 
may be not activated due to the impairment of the autocrine actions of TGF- $\beta$ (Figure 8). We also demonstrated that prorenin infusions increase the expression of profibrotic genes and fibronectin and collagen I positive staining in mice isolated CDs. Importantly, the co-treatment with a selective COX-2 inhibitor NS-398 prevented this effect, despite the activation of MAPK pathway (Figure 7). This indicates that COX-2 activity, and probably EP4 activation, is necessary for the PRR-dependent upregulation of profibrotic factors and cellular ROS generation.

At micromolar concentrations, PD98059 is a highly selective in vitro inhibitor of MEK1 activation and MAPK cascade (Alessi et al., 1995). In our experiment, two different concentrations of the inhibitor were used, based on the IC50 described with respect to the inhibition it generates in ERK $1(4 \mu \mathrm{M})$ and in ERK $2(50 \mu \mathrm{M})$ and in the evidence obtained by different authors previously (Gonzalez et al., 2017). Figure 2 shows that there is no significant difference between levels of ROS obtained for two concentrations tested; as a result, we continued working with the concentration that was previously established by our group $(30 \mu \mathrm{M})$. As shown in Figure 2, we confirmed our previous studies, which showed that ERK inhibition impairs ROS generation and profibrotic gene expression mediated by PRR stimulation. Next, we proceeded with studying the effects of NOX-4 inhibition in CD cells.

Clavreul et al. demonstrated that in HEK cells that were transfected with a siRNA targeting the PRR, the expression of NOX-4 was prevented as well as the increase in superoxide production, TGF- $\beta$, fibronectin, and PAI-1expression (Clavreul et al., 2011). Due to this evidence, we decided to use a pharmacological inhibitor of NOX-4, which is the main isoform with physiological actions in CD cells (Lu et al., 2016). The pharmacological inhibitor GKT 137831 has been described as a dual inhibitor of both NOX-4 and NOX-1 (Green et al., 2012). The effectiveness of GKT 137831 has been demonstrated in cells of the pulmonary vascular wall and cardiac fibroblasts, where it blocks the action of NOX-4 and, thereby, prevents an increase in ROS production (Green et al., 2012). To evaluate its effects on ROS generation in the M-1 CD cell line, we tested three different concentrations, based on concentrations used in the studies of Green et al. (Green et al., 2012). These concentrations were 10, 20, and $30 \mu \mathrm{M}$. As seen in Figure 2, the addition of this inhibitor prevents ROS induction in the M-1 CD cells at all three concentrations. However, we decided to work with $30 \mu \mathrm{M}$, since at this concentration, ROS generation was much closer to the control (Figure 2). NOX-4 inhibition was able to prevent the increase in ROS with respect to the basal condition, which indicates in the first instance that the main source of ROS is effectively NOX-4, which is consistent with Clavreul's evidence (Clavreul et al., 2011). GTK 137831 also prevented the increase in the synthesis of profibrotic proteins (Figure 3), indicating that the activation of NOX-4 can directly activate the production of profibrotic factors.

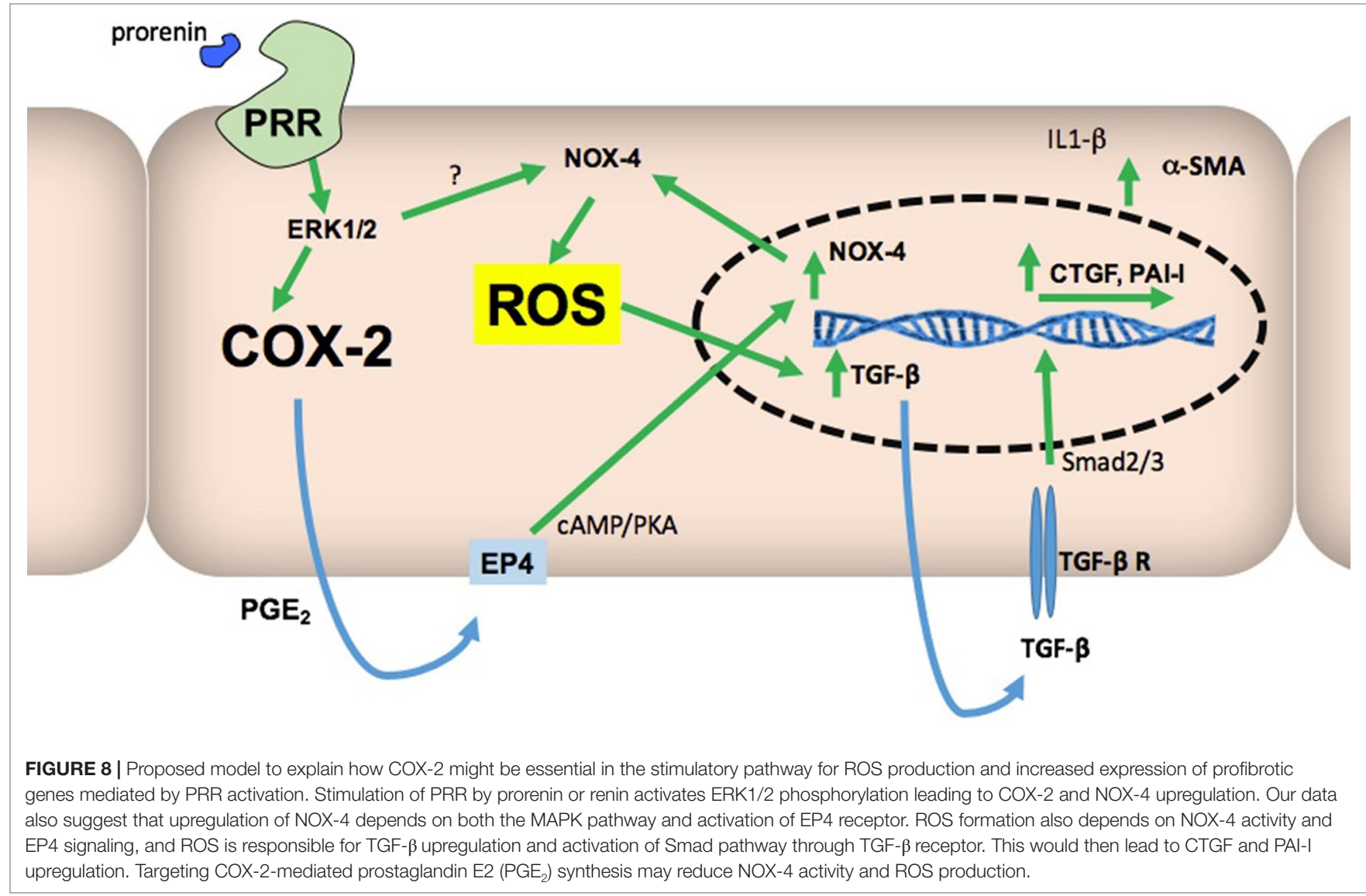


Activation of the prostaglandin receptor EP4 increases NOX-4 expression in liver cells. In addition, overexpression of COX-2 leads to higher NOX-4 levels and ROS content, while inhibition of the enzyme leads to decreased NOX-4 levels and ROS content (Sancho et al., 2011). In turn, ROS are involved in TGF- $\beta$ and Smad signaling (Lafon et al., 1996; Chiu et al., 2001), which induces fibrotic factors CTGF and PAI-I (Clarkson et al., 1999; Kilari et al., 2018). The ERK pathway can enhance Smad activity. On the other hand, ERK inhibition reduces TGF- $\beta 1$-stimulated Smad phosphorylation as well as collagen production and promoter activities, suggesting that ERK activity is necessary for an optimal response to TGF- $\beta 1$ (Hayashida et al., 2003). Although we observed a reduction in ROS production and profibrotic factors in hrPR-treated cells, the suppression was not complete. This incomplete suppression indicates that the activity of endogenous NOX-4 may be induced by MAPK pathway independent of COX-2-mediated $\mathrm{PGE}_{2}$ and EP4 activation. Furthermore, it is possible that low levels of ROS might function in various pathophysiological processes, contributing to the activation of transcription factors leading to induction of profibrotic factors as well (Sedeek et al., 2013a; Sedeek et al., 2013b). We have reported that antioxidants prevented the increase in profibrotic factors, indicating an evident role of ROS as a signaling agent in a pathophysiological process (Gonzalez et al., 2017).

Our data were corroborated in vivo using chronic infusions of human recombinant prorenin during $36 \mathrm{~h}$. We observed an increased expression of profibrotic genes in isolated CDs from treated mice through Western blot analysis of pERK and total ERK, CTGF, TGF- $\beta$, and PAI-I and by immunofluorescence analysis of fibronectin and collagen I expression (Figures 6 and 7) We also observed $\alpha$-SMA staining in mice with hrPR infusions, which was less evident in mice treated with COX-2 inhibitor. It is possible that recombinant prorenin infusion increased profibrotic protein expression through direct interactions with apical PRR by filtration from plasma and having access to the distal tubular lumen or by having access to basolateral PRR through the blood.

Despite the evidence of the role of NOX-4 and ERK pathway in renal fibrosis, little is known about their interactions with COX-2. PRR and COX-2 are co-located in CD cells (Gonzalez et al., 2013), which suggests that they could be functionally related. Kaneshiro et al. demonstrated in 2006 that the overexpression of human

\section{REFERENCES}

Alessi, D. R., Cuenda, A., Cohen, P., Dudley, D. T., and Saltiel, A. R. (1995). PD 098059 is a specific inhibitor of the activation of mitogen-activated protein kinase kinase in vitro and in vivo. J. Biol. Chem. 270, 27489-27494. doi: 10.1074/jbc. 270.46 .27489

Ballarin-Gonzalez, B., Dagnaes-Hansen, F., Fenton, R. A., Gao, S., Hein, S., Dong, M. D., et al. (2013). Protection and systemic translocation of siRNA following oral administration of chitosan/siRNA nanoparticles. Mol. Ther. Nucleic Acids 2, e76. doi: 10.1038/mtna.2013.2

Batenburg, W. W., Krop, M., Garrelds, I. M., de Vries, R., de Bruin, R. J. A., Burckle, C. A., et al. (2007). Prorenin is the endogenous agonist of the (pro) renin receptor. Binding kinetics of renin and prorenin in rat vascular smooth muscle cells overexpressing the human (pro)renin receptor. J. Hypertens. 25, 2441-2453. doi: 10.1097/HJH.0b013e3282f05bae
PRR in rats resulted in an over-regulation of COX-2 in renal cortex, which contributed to the generation of tubular damage, due to the inflammation mediated by prostaglandins (Kaneshiro et al., 2006). In addition to this evidence, it is known that the activation of MAPK activates COX-2, which consequently leads to production of $\mathrm{PGE}_{2}$ in the $\mathrm{CD}$. Furthermore, we have recently published evidence of the participation of $\mathrm{PGE}_{2}$, synthesized by $\mathrm{COX}-2$, in the regulation of prorenin. Prorenin causes further increases in COX-2 expression, generating transient COX2-prorenin positive feedback (Salinas-Parra et al., 2017). As mentioned before, the relationship between COX-2 and NOX-4 observed in hepatocytes (Sancho et al., 2011) suggests that a similar system regulated by positive feedback may be present in CD cells (Figure 8).

In summary, our results indicate that the induction of ROS, TGF- $\beta$, and profibrotic factors CTGF and PAI-I occurs through PRR-dependent activation of MAPK and NOX-4. Additionally, it depends on intact COX-2 activity that leads to $\mathrm{PGE}_{2}$-dependent activation of EP4 receptor and TGF- $\beta$ receptor-dependent Smad pathway activation. Site-specific pharmacological inhibition of COX-2 in the CD may help to prevent tubular damage during states of activation of intratubular renin-angiotensin system, such as hypertension and diabetes.

\section{ETHICS STATEMENT}

The Institutional Animal Care and Use Committees of the Pontificia Universidad Catolica de Valparaiso approved all animal protocols.

\section{AUTHOR CONTRIBUTIONS}

AG, CR-M, MK, and QMN performed the experiments, analyzed the data and provided the final version of the manuscript.

\section{FUNDING}

This study was funded by DI Grant No 0.39.307/2018 Pontificia Universidad Católica de Valparaíso, Chile and Fondo Nacional de Desarrollo Científico y Tecnológico (FONDECYT) 1191006.

Burckle, C. A., Danser, A. H. J., Muller, D. N., Garrelds, I. M., Gasc, J. M. Popova, E., et al. (2006). Elevated blood pressure and heart rate in human renin receptor transgenic rats. Hypertension 47, 552-556. doi: 10.1161/01. HYP.0000199912.47657.04

Campbell, D. J., Nussberger, J., Stowasser, M., Danser, A. H. J., Morganti, A., Frandsen, E., et al. (2009). Activity assays and immunoassays for plasma renin and prorenin: information provided and precautions necessary for accurate measurement. Clin. Chem. 55, 867-877. doi: 10.1373/clinchem.2008.118000

Chi, Y. C., Shi, C. L., Zhou, M., Liu, Y., Zhang, G., and Hou, S. A. (2017). Selective cyclooxygenase-2 inhibitor NS-398 attenuates myocardial fibrosis in mice after myocardial infarction via Snail signaling pathway. Eur. Rev. Med. Pharmacol. Sci. 21, 5805-5812. doi: 10.26355/eurrev_201712_14028

Chiarelli, F., Pomilio, M., De Luca, F. A., Vecchiet, J., and Verrotti, A. (2001). Plasma prorenin levels may predict persistent microalbuminuria in children with diabetes. Pediatr. Nephrol. 16, 116-120. doi: 10.1007/s004670000514 
Chiu, C., Maddock, D. A., Zhang, Q., Souza, K. P., Townsend, A. R., and Wan, Y. (2001). TGF-beta-induced p38 activation is mediated by Racl-regulated generation of reactive oxygen species in cultured human keratinocytes. Int. J. Mol. Med. 8, 251-255. doi: 10.3892/ijmm.8.3.251

Clarkson,M.R., Gupta,S., Murphy,M., Martin,F., Godson, C., andBrady,H.R.(1999). Connective tissue growth factor: a potential stimulus for glomerulosclerosis and tubulointerstitial fibrosis in progressive renal disease. Curr. Opin. Nephrol. Hypertens. 8, 543-548. doi: 10.1097/00041552-199909000-00002

Clavreul, N., Sansilvestri-Morel, P., Magard, D., Verbeuren, T. J., and Rupin, A. (2011). (Pro)renin promotes fibrosis gene expression in HEK cells through a Nox4-dependent mechanism. Am. J. Physiol. Renal. 300, F1310-F1318. doi: 10.1152/ajprenal.00119.2010

Feldt, S., Batenburg, W. W., Mazak, I., Maschke, U., Wellner, M., Kvakan, H., et al. (2008). Prorenin and renin-induced extracellular signal-regulated kinase 1/2 activation in monocytes is not blocked by aliskiren or the handle-region peptide. Hypertension 51, 682-688. doi: 10.1161/HYPERTENSIONAHA.107.101444

Ferguson, S., Hebert, R. L., and Laneuville, O. (1999). NS-398 upregulates constitutive cyclooxygenase- 2 expression in the M-1 cortical collecting duct cell line. J. Am. Soc. Nephrol. 10, 2261-2271.

Franken, A. A. M., Derkx, F. H. M., Blankestijn, P. J., Janssen, J.A.M.J.L., Mannesse, C. K., Hop, W., et al. (1992). Plasma prorenin as an early marker of microvascular disease in patients with diabetes-mellitus. Diabetes Metab. 18, 137-143.

Gonzalez, A. A., Cifuentes-Araneda, F., Ibaceta-Gonzalez, C., Gonzalez-Vergara, A., Zamora, L., Henriquez, R., et al. (2016). Vasopressin/V2 receptor stimulates renin synthesis in the collecting duct. Am. J. Physiol. Renal. 310, F284-F293. doi: 10.1152/ajprenal.00360.2015

Gonzalez, A. A., Green, T., Luffman, C., Bourgeois, C. R., Gabriel Navar, L., and Prieto, M. C. (2014). Renal medullary cyclooxygenase-2 and (pro)renin receptor expression during angiotensin II-dependent hypertension. Am. J. Physiol. Renal Physiol. 307, F962-F970. doi: 10.1152/ajprenal.00267.2014

Gonzalez, A. A., Lara, L. S., Luffman, C., Seth, D. M., and Prieto, M. C. (2011). Soluble form of the (pro) renin receptor is augmented in the collecting duct and urine of chronic angiotensin ii-dependent hypertensive rats. Hypertension 57, 859-864. doi: 10.1161/HYPERTENSIONAHA.110.167957

Gonzalez, A. A., Liu, L., Lara, L. S., Bourgeois, C. R., Ibaceta-Gonzalez, C., SalinasParra, N., et al. (2015). PKC-alpha-dependent augmentation of cAMP and CREB phosphorylation mediates the angiotensin II stimulation of renin in the collecting duct. Am. J. Physiol. Renal Physiol. 309, F880-F888. doi: 10.1152/ ajprenal.00155.2015

Gonzalez, A. A., Liu, L., Lara, L. S., Seth, D. M., Navar, L. G., and Prieto, M. C. (2011). Angiotensin II stimulates renin in inner medullary collecting duct cells via protein kinase $\mathrm{C}$ and independent of epithelial sodium channel and mineralocorticoid receptor activity. Hypertension 57, 594-599. doi: 10.1161/ HYPERTENSIONAHA.110.165902

Gonzalez, A. A., Luffman, C., Bourgeois, C. R., Vio, C. P., and Prieto, M. C. (2013). Angiotensin II-independent upregulation of cyclooxygenase-2 by activation of the (Pro)renin receptor in rat renal inner medullary cells. Hypertension 61, 443-449. doi: 10.1161/HYPERTENSIONAHA.112.196303

Gonzalez, A. A., Salinas-Parra, N., Leach, D., Navar, L. G., and Prieto, M. C. (2017). PGE2 upregulates renin through E-prostanoid receptor 1 via PKC/ cAMP/CREB pathway in M-1 cells. Am. J. Physiol. Renal. 313, F1038-F1049. doi: 10.1152/ajprenal.00194.2017

Gonzalez, A. A., Zamora, L., Reyes-Martinez, C., Salinas-Parra, N., Roldan, N., Cuevas, C. A., et al. (2017). (Pro)renin receptor activation increases profibrotic markers and fibroblast-like phenotype through MAPK-dependent ROS formation in mouse renal collecting duct cells. Clin. Exp. Pharmacol. Physiol. 1134-1144. doi: 10.1111/1440-1681.12813

Green, D. E., Murphy, T. C., Kang, B. Y., Kleinhenz, J. M., Szyndralewiez, C., Page, P., et al. (2012). The Nox4 inhibitor GKT137831 attenuates hypoxia-induced pulmonary vascular cell proliferation. Am. J. Respir. Cell Mol. Biol. 47, 718-726. doi: 10.1165/rcmb.2011-0418OC

Hayashida, T., Decaestecker, M., and Schnaper, H. W. (2003). Cross-talk between ERK MAP kinase and Smad signaling pathways enhances TGF-beta-dependent responses in human mesangial cells. FASEB J. 17, 1576-1578. doi: 10.1096/ fj.03-0037fje

Hong, Y. H., Peng, H. B., La Fata, V., and Liao, J. K. (1997). Hydrogen peroxidemediated transcriptional induction of macrophage colony-stimulating factor by TGF-beta1. J. Immunol. 159, 2418-2423.
Huang, J. Q., and Siragy, H. M. (2009). Glucose Promotes the production of interleukine-1 beta and cyclooxygenase- 2 in mesangial cells via enhanced (pro)renin receptor expression. Endocrinology 150, 5557-5565. doi: 10.1210/ en.2009-0442

Huang, J. Q., and Siragy, H. M. (2010). Regulation of (pro) renin receptor expression by glucose-induced mitogen-activated protein kinase, nuclear factor-kappa B, and activator protein-1 signaling pathways. Endocrinology 151, 3317-3325. doi: 10.1210/en.2009-1368

Huang, J. Q., Matavelli, L. C., and Siragy, H. M. (2011). Renal (pro)renin receptor contributes to development of diabetic kidney disease through transforming growth factor-beta 1-connective tissue growth factor signalling cascade. Clin. Exp. Pharmacol. P 38, 215-221. doi: 10.1111/j.1440-1681.2011.05486.x

Ichihara, A., Sakoda, M., Kurauchi-Mito, A., Nishiyama, A., and Itoh, H. (2008). Involvement of receptor-bound prorenin in development of nephropathy in diabetic db/db mice. J. Am. Soc. Hypertens. 2, 332-340. doi: 10.1016/j. jash.2008.04.009

Kaneshiro, Y., Ichihara, A., Sakoda, M., Takemitsu, T., Nabi, A. H. M. N., Uddin, M. N., et al. (2007). Slowly progressive, angiotensin II-independent glomerulosclerosis in human (pro)renin receptor-transgenic rats. J. Am. Soc. Nephrol. 18, 1789-1795. doi: 10.1681/ASN.2006091062

Kaneshiro, Y., Ichihara, A., Takemitsu, T., Sakoda, M., Suzuki, F., Nakagawa, T., et al. (2006). Increased expression of cyclooxygenase- 2 in the renal cortex of human prorenin receptor gene-transgenic rats. Kidney Int. 70, 641-646. doi: 10.1038/sj.ki.5001627

Kang, J. J., Toma, I., Sipos, A., Meer, E. J., Vargas, S. L., and Peti-Peterdi, J. (2008). The collecting duct is the major source of prorenin in diabetes. Hypertension 51, 1597-1604. doi: 10.1161/HYPERTENSIONAHA.107.107268

Kilari, S., Yang, B., Sharma, A., McCall, D. L., and Misra, S. (2018). Increased transforming growth factor beta (TGF-beta) and pSMAD3 signaling in a murine model for contrast induced kidney injury. Sci. Rep. 8, 6630. doi: 10.1038/s41598-018-24340-z

Lafon, C., Mathieu, C., Guerrin, M., Pierre, O., Vidal, S., and Valette, A. (1996). Transforming growth factor beta 1-induced apoptosis in human ovarian carcinoma cells: protection by the antioxidant N-acetylcysteine and bcl-2. Cell Growth Differ. 7, 1095-1104.

Lenz, T., Sealey, J. E., Lappe, R. W., Carilli, C., Oshiro, G. T., Baxter, J. D., et al. (1990). Infusion of recombinant human prorenin into rhesus monkeys. Effects on hemodynamics, renin-angiotensin-aldosterone axis and plasma testosterone. Am. J. Hypertens. 3, 257-261. doi: 10.1093/ajh/3.4.257

Lu, X., Wang, F., Liu, M., Yang, K. T., Nau, A., Kohan, D. E., et al. (2016). Activation of $\mathrm{ENaC}$ in collecting duct cells by prorenin and its receptor PRR: involvement of Nox4-derived hydrogen peroxide. Am. J. Physiol. Renal Physiol. 310, F1243F1250. doi: 10.1152/ajprenal.00492.2015

Lugarini, F., Hrupka, B. J., Schwartz, G. J., Plata-Salaman, C. R., and Langhans, W. (2002). A role for cyclooxygenase-2 in lipopolysaccharide-induced anorexia in rats. Am. J. Physiol. Regul. Integr. Comp. Physiol. 283, R862-R868. doi: 10.1152/ ajpregu.00200.2002

Meng, X. M., Tang, P. M., Li, J., and Lan, H. Y. (2015). TGF-beta/Smad signaling in renal fibrosis. Front. Physiol. 6, 82. doi: 10.3389/fphys.2015.00082

Muller, D. N., Klanke, B., Feldt, S., Cordasic, N., Hartner, A., Schmieder, R. E., et al. (2008). (Pro) renin receptor peptide inhibitor "handle-region" peptide does not affect hypertensive nephrosclerosis in Goldblatt rats. Hypertension 51, 676-681. doi: 10.1161/HYPERTENSIONAHA.107.101493

Muzaffar, S., Jeremy, J. Y., Angelini, G. D., and Shukla, N. (2012). NADPH oxidase 4 mediates upregulation of type 4 phosphodiesterases in human endothelial cells. J. Cell. Physiol. 227, 1941-1950. doi: 10.1002/jcp.22922

Nasrallah, R., Laneuville, O., Ferguson, S., and Hebert, R. L. (2001). Effect of COX-2 inhibitor NS-398 on expression of $\mathrm{PGE}(2)$ receptor subtypes in M-1 mouse CCD cells. Am. J. Physiol. Renal. 281, F123-F132. doi: 10.1152/ ajprenal.2001.281.1.F123

Nguyen, G., and Burckle, C. A. (2004). The (pro)renin receptor: biology and functional significance. B. Acad. Nat. Med. Paris 188, 621-628.

Nguyen, G., and Contrepas, A. (2008). Physiology and pharmacology of the (pro)renin receptor. Curr. Opin. Pharmacol. 8, 127-132. doi: 10.1016/j. coph.2007.12.009

Nguyen, G., Burckle, C. A., and Sraer, J. D. (2004). Renin/prorenin-receptor biochemistry and functional significance. Curr. Hypertens. Rep. 6, 129-132. doi: $10.1007 /$ s11906-004-0088-3 
Nguyen, G., Delarue, F., Burckle, C., Bouzhir, L., Giller, T., and Sraer, J. D. (2002). Pivotal role of the renin/prorenin receptor in angiotensin II production and cellular responses to renin. J. Clin. Invest. 109, 1417-1427. doi: 10.1172/JCI0214276

Prieto-Carrasquero, M. C., Botros, F. T., Pagan, J., Kobori, H., Seth, D. M., Casarini, D. E., et al. (2008). Collecting duct renin is upregulated in both kidneys of 2-kidney, 1-clip Goldblatt hypertensive rats. Hypertension 51, 1590-1596. doi: 10.1161/HYPERTENSIONAHA.108.110916

Prieto-Carrasquero, M. C., Harrison-Bernard, L. M., Kobori, H., Ozawa, Y., Hering-Smith, K. S., Hamm, L. L., et al. (2004). Enhancement of collecting duct renin in angiotensin II-dependent hypertensive rats. Hypertension 44, 223-229. doi: 10.1161/01.HYP.0000135678.20725.54

Salinas-Parra, N., Reyes-Martinez, C., Prieto, M. C., and Gonzalez, A. A. (2017). Prostaglandin E2 induces prorenin-dependent activation of (pro)renin receptor and upregulation of cyclooxygenase- 2 in collecting duct cells. Am. J. Med. Sci. 354, 310-318. doi: 10.1016/j.amjms.2017.05.018

Sancho, P., Martin-Sanz, P., and Fabregat, I. (2011). Reciprocal regulation of NADPH oxidases and the cyclooxygenase-2 pathway. Free Radic. Biol. Med. 51, 1789-1798. doi: 10.1016/j.freeradbiomed.2011.08.011

Sedeek, M., Gutsol, A., Montezano, A. C., Burger, D., Nguyen Dinh Cat, A., Kennedy, C. R., et al. (2013a). Renoprotective effects of a novel Nox1/4 inhibitor in a mouse model of Type 2 diabetes. Clin. Sci. (Lond.) 124, 191-202. doi: 10.1042/ CS20120330

Sedeek, M., Nasrallah, R., Touyz, R. M., and Hebert, R. L. (2013b). NADPH oxidases, reactive oxygen species, and the kidney: friend and foe. J. Am. Soc Nephrol. 24, 1512-1518. doi: 10.1681/ASN.2012111112

Stoos, B. A., Narayfejestoth, A., Carretero, O. A., Ito, S., and Fejestoth, G. (1991). Characterization of a mouse cortical collecting duct cell-line. Kidney Int. 39, 1168-1175. doi: 10.1038/ki.1991.148

Takayama, K., Garcia-Cardena, G., Sukhova, G. K., Comander, J., Gimbrone, M. A., and Libby, P. (2002). Prostaglandin E-2 suppresses chemokine production in human macrophages through the EP4 receptor. J. Biol. Chem. 277, 4414744154. doi: 10.1074/jbc.M204810200
Tu, W., Eckert, G. J., Pratt, J. H., and Jan Danser, A. H. (2012). Plasma levels of prorenin and renin in blacks and whites: their relative abundance and associations with plasma aldosterone concentration. Am. J. Hypertens. 25, 1030-1034. doi: 10.1038/ajh.2012.83

Wang, F., Lu, X., Peng, K., Fang, H., Zhou, L., Su, J., et al. (2016). Antidiuretic action of collecting duct (pro)renin receptor downstream of vasopressin and PGE2 receptor EP4. J. Am. Soc. Nephrol. 27, 3022-3034. doi: 10.1681/ ASN.2015050592

Wilkinson-Berka, J. L. (2008). Prorenin and the (pro)renin receptor in ocular pathology. Am. J. Pathol. 173, 1591-1594. doi: 10.2353/ajpath.2008.080757

Yisireyili, M., Saito, S., Abudureyimu, S., Adelibieke, Y., Ng, H. Y., Nishijima, F., et al. (2014). Indoxyl sulfate-induced activation of (pro)renin receptor promotes cell proliferation and tissue factor expression in vascular smooth muscle cells. PLoS One 9 (10), e109268. doi: 10.1371/journal.pone.0109268

Yoshida, G., Kawasaki, M., Murata, I., Hayakawa, Y., Aoyama, T., Miyazaki, N., et al. (2015). Higher plasma prorenin concentration plays a role in the development of coronary artery disease. Biomark. Res. 3, 18. doi: 10.1186/ s40364-015-0044-1

Conflict of Interest Statement: The authors declare that the research was conducted in the absence of any commercial or financial relationships that could be construed as a potential conflict of interest.

The handling editor declared a shared affiliation, though no other collaboration, with the authors CR-M and AG, at the time of review.

Copyright (C) 2019 Reyes-Martinez, Nguyen, Kassan and Gonzalez. This is an openaccess article distributed under the terms of the Creative Commons Attribution License (CC BY). The use, distribution or reproduction in other forums is permitted, provided the original author(s) and the copyright owner(s) are credited and that the original publication in this journal is cited, in accordance with accepted academic practice. No use, distribution or reproduction is permitted which does not comply with these terms. 